\title{
A patient led, international study of long term outcomes of oesophageal atresia: EAT 1
}

Evelyn Svoboda ${ }^{a}$, JoAnne Fruithof ${ }^{a}$, Anke Widenmann-Grolig ${ }^{a}$, Graham Slater $^{\mathrm{a}}$, Frederic Armand ${ }^{\mathrm{a}}$, Bernhard Warner ${ }^{\mathrm{a}}$, Simon Eaton ${ }^{\mathrm{b}}$ Paolo De Coppi ${ }^{\mathrm{b}}$, Edward Hannon ${ }^{\mathrm{b}}$.

a) The Federation of Esophageal Atresia and Tracheo-Esophageal Fistula support groups. Sommerrainstrasse 61, 70374 Stuttgart, Germany.

b) UCL Great Ormond Street Institute of Child Health, 30 Guilford St, London, WC1N 1EH

\section{Corresponding Author}

Edward Hannon

UCL Great Ormond Street Institute of Child Health

30 Guilford St,

London,

WC1N 1EH

Email: edward.hannon@ucl.ac.uk

Telephone: 02079052158 


\section{Background:}

Outcomes in oesophageal atresia (OA) have improved in the last 50 years with survival now of more than $90 \%$ [1-3] leading to an increasing population of long term survivors. Whilst our understanding of short term outcomes in infants with $\mathrm{OA}$ is good [4-7], longer term functional outcomes are more poorly understood with a limited research base [8-10]. There is increasing interest therefore in longer term outcome studies, and results of such studies potentially impact current practice in management of OA. This may be especially important for transitional care as patients leave the care of the paediatric surgeon for the adult world. The current literature tends to be limited to small national [4, 9] and institutional datasets or meta-analysis of such studies [8]. Patient reported outcomes (PROMS), as an adjunct to reporting of outcomes by physicians and surgeons are becoming increasingly recognised as very important for improving care in a variety of conditions [11, 12].

The Federation of Esophageal Atresia and Tracheo-Esophageal Fistula support groups (EAT) is an international federation of patient support groups (Table 1), led by patients and parents aiming to share the international knowledge and experience of $\mathrm{OA}$, promote awareness of the condition across the world and support worldwide research and collation of information concerning the treatment and care of people born with esophageal atresia. EAT therefore has a keen interest in the short and long term outcomes of OA and have first-hand experience of the difficulties faced by many patients and carers at all times in their journey from diagnosis though transition and on into adult care. In order to gain an idea of the patient-reported outcomes in OA, EAT has conducted a patient and carer designed and led study. This paper aims to report the data from this unique study in order to provide insight into patient-reported short and long term outcomes of OA in a large international cohort of patients with OA. 


\section{Methods:}

This study was conceptualised as a questionnaire which was then designed by the board of EAT (see author list) with support from a Professor of Quality of Care (MvD). It was designed to be a patient / carer focussed study looking at outcomes of specific interest to those groups. The questionnaire was therefore designed to assess the following keys areas of interest:

1. Current symptomatology

2. Patient / carer satisfaction

3. Quality of life (QoL)

Demographics and operative details were also obtained as part of the questionnaire in order to describe the OA population surveyed. A questionnaire then piloted within the EAT board, prepared in multiple languages (English, Dutch, German, French and Italian) and put in an electronic format using SurveyMonkey ${ }^{\circledR}$. Invitations to participate were sent electronically to all members of 11 different European patient support groups (Table 1). This included patients and carers in 24 different countries, as members of the support groups sometimes resided outside of Europe.

Where possible, patients completed the questionnaire; otherwise this was performed by carers. Completed questionnaire were collected centrally, collated and analysed anonymously. Initial data was presented by the Chairman of EAT at British Association of Paediatric Surgeons Congress (Cardiff, 2015). Following this the organisation approached UCL Institute of Child Health for assistance in data analysis and interpretation. Formal ethics approval was not initially sought as this was a patient group led study. Approval was obtained for anonymised data analysis from ICH / GOSH Research \& Development office at (project number 16DS21). Initial data were cleaned and duplicate responses excluded, together with responses where date of birth was not completed. Responses with missing or duplicate data for individual questions were included for those questions answered and percentages calculated from only completed answers.

Patient height and weight were analysed using standard deviation scores (SDS) using LMS Growth Excel Plug In version 2.69 and UK-WHO Growth Charts in respondents under 18 years old. Body mass index was calculated for those 18 years and over and compared to the WHO International Classification. Data were compared by Fisher's exact test or Mann-Whitney, regarding $p=0.05$ as the cut-off for significance. 


\section{Results:}

Demographics

1100 responses were received from an estimated 2500 members of EAT organisations invited to participate. Following exclusions, 928 responses (56\% male and $44 \%$ female) were analysed with a patient age range of 1 month to 60 years of age. For analysis, patients were divided into the following age groups, $<5$ years (42\% of responses), 5-10 years (26\%), $11-17$ years (16\%) and 18 years and over (16\%).

Responses were received from 25 different countries (Figure 1). Smaller numbers of responses were also received from Canada, USA, Ireland, South Africa, New Zealand, Spain, Guadeloupe, Tunisia, Sweden, Malta, Lithuania, Israel, Hungary, Hong Kong, Greece and Denmark in decreasing order of number of responses. $121(18 \%)$ of responses were completed by patients and 761 (82\%) by a parent or carer.

OA with trachea-oesophageal fistula (OA-TOF) was the most common defect, reported in $80 \%$ of cases, $19 \%$ were pure $\mathrm{OA}$ and $1 \%$ an $\mathrm{H}$ type fistula. Participants reported their defect as 'long gap' either as supplementary to reporting the anatomy of their defect or as an isolated diagnosis in $18 \%$ of cases. Similar distribution of type of defect was seen in all age groups although there was a significantly higher proportion of pure OA and long gap participants in the adult age group with $13 \%$ of cases being pure OA in participants under 18 versus $23 \%$ in the adult cohort $(p=0.004)$.

\section{Surgical Care}

Overall, the median length of hospital stay following initial surgery was 6 weeks (range 1 to 174 weeks). However, considering only the respondents over 18 , the median length of was 8 weeks (IQR $=16$ ). When compared by diagnosis, those with OA-TOF had a median LoS of 6 weeks (IQR) versus 8 weeks for those with pure OA (IQR). Long gap cases reported median LoS was 18 weeks (IQR) versus 5 weeks (IQR) for standard gap OA. Fifty-three percent (0-5 years), 46\% (5-10 years) and 52\% (11-17 years) of participants in the younger age groups respectively only required 1 operation to repair their defect, whereas in the 18 year and above group only $36 \%$ were repaired with a single operation and $45 \%$ needed $2-5$ procedures.

The proportion of patients receiving dilatation following repair is summarised in Figure 2. Forty-nine percent of all respondents had oesophageal dilatation and the number of dilatations received was broadly similar across each age group. If dilatation was performed the median number was 4 dilatations and was the same for all age groups. The median number of reported dilatations in participants with long gap OA was 2 (IQR 0-10) and was significantly higher $(p<0.001)$ than in those with standard gap who reported a median of 0 dilatations (IQR $0-5$ ). Those respondents reporting reflux symptoms had a significantly higher median number of dilatations at 1 (IQR 0-5) than those without symptoms where the median number of dilatations was 0 (IQR $0-3 ; p=0.01)$.

\section{Symptomatology}

Across all participants, 65\% reported that they could 'eat anything' with no restrictions on type of food. In those under 5 years, this figure was only $50 \%$ which was significantly less than those over 5 years old in which $75 \%$ reported they could 'eat anything' $(p<0.0005)$. In those with long gap defects, only $35 \%$ of those under 10 reported that they could eat without restriction.

Figure 3 shows how frequently participants in different age groups reported food getting stuck in the oesophagus. The patterns across age groups are broadly similar with $16 \%$ of participants often 
getting food stuck and only $22 \%$ reporting never having food stick. Over $50 \%$ of adult patients (18 years and above) report sometimes or often getting food stuck in the oesophagus.

$58 \%$ percent of respondents reported gastro oesophageal reflux symptoms and a similar incidence was seen in all age groups; $65 \%$ in $<5$ years, $53 \%$ in $5-10$ years, $54 \%$ in $11-17$ years and $60 \%$ in adults. When analysed by gap length, $78 \%$ of those with long gap defects reported suffering from reflux symptoms versus $55 \%$ of respondents with standard gap length $(p<0.005)$. The use of anti-reflux medication showed a decreasing trend with age. Reflux medication was reported being taken by $60 \%$ of under 5 s but only $30 \%$ of adult participants, despite a similar proportion in each age group reporting symptoms.

Respiratory problems were commonly reported by participants and show a decreasing trend with age. (Fig 4). Patients with long gap OA more often reported respiratory symptoms with $42 \%$ of under 5 s and $24 \%$ of 5-10 year old with long-gap reporting 'often' having symptoms compared to $16 \%$ and $8 \%$ respectively in standard gap patients. There is a similar decreasing trend with age in the incidence of chest infections with $30 \%$ of children under 5 years reporting having more than 3 chest infection per year but only $14 \%$ of adults reporting the same frequency of infections (Figure 5). Long gap patients did not report more frequently occurring chest infections than standard gap patients except in the under 5's.

Regular antibiotic usage has shown similar decreasing trend in the use of with $17 \%$ of $0-10$ year olds reporting regularly needing antibiotics, falling to $9 \%(11-17)$ and $5 \%(>18)$ in the older age groups respectively.

\section{Anthropometry}

On average, children $<18$ years with $\mathrm{OA}$ were slightly less than average weight and height, with median SDS scores of -0.41 (IQR -1.4 to +0.67$)$ for height and -0.63 (IQR -1.6 to 0.17 ) for weight, where population averages are zero (Fig $6 \mathrm{~A}$ ). BMI in respondents 18 years and over is shown in Figure $6 \mathrm{~B}$. Two percent of adult respondents reported weight and height that put them in the obese BMI category, $15 \%$ were overweight, $62 \%$ were normal weight and $21 \%$ were underweight. The mean BMI was 21.5.

\section{Care Provision}

Current care provision is shown in Figure 7. Twenty-two percent of children under 5 are reported not to be under the care of a paediatric surgeon and there is a trend of fewer participants being looked after by paediatric surgeons with increasing age. There is also an increasing trend with age in those with no current care provider with $50 \%$ of adults not reported being looked after by a general practitioner or equivalent primary care physician.

\section{Quality of life}

The graphs in figure 8 A-D show responses to the questions related to quality of life in the study. They demonstrate that whilst $20-25 \%$ of respondents report that OA has had no effect on their own or their families QoL a similar proportion of patients suggested their QoL was significantly affected. Over $55 \%$ of respondents report 'some' or a 'significant' effect on their family's QoL. 


\section{Discussion:}

The EAT 1 survey offers unique, international patient directed short, medium and long term follow up data on one the largest cohorts of OA patients in the literature to date. It highlights the clinical long term morbidity that OA patients suffer from and how these may change with age. It also importantly examines the often ignored quality of life issues faced by this patient group. The large size of this study group makes it more representative of the wider international population of OA patients than most of the existing literature which is limited to smaller national $[4,10]$ and institutional data series [3, 7, 13] or meta-analyses [8]. The study participants are broadly representative of the wider population based on anatomy of original defect in comparison to EUROCAT figures [14]. The significantly higher incidence of pure and long gap OA in the adult group probably represents the demographics of adult patients accessing support groups i.e. those with more complex conditions and a similar pattern of recruitment is seen in the German support group (KEKS) quality of life (QoL) study [15]. While ongoing care is expected for most complex patients during their adult life, this is also one of the limitations of studies like ours in which responders are recruited via a patient specific association and should be taken into account during counselling. The age range of participants studied again makes this study unique including infants up to the oldest subject who was 60 years of age at completion of the survey. The fewer patients in the older age range may be the result of several factors including the previous limited survival of babies in the early years of OA surgery, the relatively new development of patient support groups - through which recruitment took place and also the perceived need of such support groups in older patients. The geographic spread of participants represents the principal patient support groups involved in the study and membership in each of those countries.

The anthropometric data collected in this study is consistent with existing literature [16-18] suggesting that as children, patients with $O A$ tend toward being underweight and to a less extent shorter than the normal population. Interestingly, we showed a significantly lower mean score for height in under $5 \mathrm{~s}$ than older children. It may represent a sampling weakness as these were selfrecorded and reported outcomes in an age group in which it may be difficult to get accurate length/height measurements. Chetcuti et al reported that there is 'catch up' growth as children become adolescents and then adults[17]. The median BMI of the adult group is within the normal range at 21.5 suggesting catch-up growth, although there are still $21 \%$ of adults classed as underweight by $\mathrm{BMI}$ and a much lower level of obesity $(2 \%)$ in this patient population than in the normal European population (15-30\%).

The post-operative management of OA has improved over the last 2 decades and this may explain the shorter length of stay seen in the younger participants. However, the groups are not evenly matched for type of defect and gap length and the higher incidence of long gap and pure OA in the adult group may account for the increased median length of stay and number of operation required.

With increasing clinical and research interest in the long term follow up of OA patients, reported outcomes relating to symptomatology and quality of life in such a large patient cohort are important additions to the literature. Dysphagia and reflux are well reported in the short and long term after OA repair and we see a high reported incidence of food 'getting stuck', a surrogate patient reported outcome for dysphagia, in agreement with published literature [8] [16]. Previous studies have reported reflux symptoms in nearly $50 \%$ of under 5 's with a decreasing frequency with age. We however found a higher reported incidence of reflux in the under 5's (65\%) and this did not decrease significantly with age with $60 \%$ of adults reporting symptoms. Meta-analysis reports a lower $(40 \%$, range 18-64\%) of reflux symptoms but recognises the variation in definition of GOR across studies analysed. We are also limited in our analysis by the lack of definition of our patient report outcomes 
but our findings add to the increasing body of literature highlighting long term morbidity in adult OA patients. The limited use of reflux medication in our adult cohort (30\%), despite the high reported incidence of symptoms (60\%was striking and is similar to that reported [19]. Schneider et al. went on to endoscope a cohort of adult OA patients and concerningly found that $67 \%$ of patients had histological evidence of oesophagitis and 43\% Barrett's oesophagus [19]. Several other studies report an increased risk of Barrett's $[9,20]$ in $O A$ and whilst a definitive increased risk of oesophageal cancer in OA patients has yet to be proven $[8,21]$ the frequency of reflux symptoms in this patient group and histological metaplastic changes mean more attention needs to be paid to the consideration of surveillance endoscopy and use of anti-reflux medication in the adult aged OA population.

Respiratory symptoms are another important morbidity following OA repair, with $38 \%$ of all patients and $39 \%$ of adult patients reporting sometimes or often suffering from respiratory symptoms a figure. Respiratory infections however do appear to be less frequent in the older patients with nearly $30 \%$ of under 5 year olds having $>3$ chest infections per year, falling to $8 \%$ and $13 \%$ in the older age groups. Connors et al suggested an overall prevalence of $24 \%$ for respiratory tract infections but with a range of $9.5-51 \%$ [8]. It is difficult to accurately compare the data from our study and to calculate the prevalence but the there is a similar message that whilst respiratory tract infections may decrease in frequency with age a third of patients with OA report ongoing respiratory symptoms though school years and adulthood.

The ongoing gastroenterological and respiratory morbidity in OA patients leads to the question of who provides care for this patient group. Whilst there is international variation in the way care is provided to these patients what is clear is that whilst only $5-10 \%$ of children under 10 years have no documented care provider (which remains concerning), this increases to $49 \%$ in the adults. Although it is possible that some adult patients have no medical input because they are asymptomatic and feel that they do not 'need' regular medical input, the high incidence of reflux and respiratory symptoms seen in this and other studies may suggest more patients should have a regular care provider with experience in OA / TOF, and that the higher number of adults not under regular care may reflect the relatively recent emphasis that is being put on transitional care and long term outcomes. This is an area of great concern to many patients.

As expected in our study there is a decrease with age in the number of patients looked after by paediatric surgeons. This may be a result of differences in practice across the countries in the study, where the longer term care of $\mathrm{OA}$ is led by gastroenterologists as opposed to surgeons or that if children are well they may be referred back to primary care. Adult patients appear to be discharged or transitioned to the gastroenterologist who provide the care to $28 \%$ of those over 18 years in our study. How transition is managed in the future is an important issue for OA care and other chronic paediatric conditions, as the population of long term survivors continues to increase. International studies such as this alongside work from Australia [22], Finland [9, 10] Holland [23, 24] and more recently the USA [25] are key in highlighting the need for careful planning of patient centred transitional and adult care. This may include the need for some stratification of transition and follow up. Our results demonstrate a wide spectrum of morbidity experienced by OA patients, many may therefore need minimal long term follow up whilst others with more significant morbidity will require regular tertiary level or hospital follow up. Early characterisation of patients 'at risk' of long term problems from more detailed future studies may help streamline the transition process.

Forward thinking centres are already looking at ways to improve the transitional care process with a German centres offering education sessions for OA patients coming up to transition [26] and there is an increasing research effort examining what improves transition across all conditions [27]. 
Quality of life in OA patients is an outcome that had limited attention from surgeons in the past but is of increasing interest. These data show that $17 \%$ of patients / parents report a 'significantly' affected QoL and demonstrate more attention needs to be paid in this area - especially as $21 \%$ and $27 \%$ also report 'significant' effects on education or work and other family members respectively. QoL in OA has been reported as being 'comparable' with the normal population by the German support group (KEKS)[15]. They did however also find that health related quality of life (HRQoL) in adults is negatively affected by disease specific symptoms such as reflux and respiratory symptoms, a result also seen in other QoL studies $[28,29]$. It is difficult to make direct comparisons between this and other QoL studies, as this study used patient-led questionnaires whereas other studies have used validated QoL tools. Nevertheless, the parent/patient led description of impaired QoL, and the finding that nearly $90 \%$ of parents of under 5 year olds reporting an effect on their child's education demands attention.

Comparison of our results to that of the KEKS study is useful as both studies examine outcomes of patients identified through patient support groups. However the use of support groups for recruitment may bias results and make comparison to the wider OA population difficult as their membership may be made up of those who require more 'support' and have a higher severity of disease. The variability in recruitment in different counties probably represents the activity and membership of the different national support organisations of EAT as opposed to proportional size of OA populations in each country. Therefore comparison of outcomes between countries is not possible and generalization of results across countries must be done with caution.

The questionnaire used in this study was specifically patient designed and easy to understand and complete and whilst this maximised recruitment it did lead to data being limited in detail for example of comorbidities and specific surgical detail. As a pilot study however its strengths lie in the numbers of participants recruited across over 20 countries and firmly establishing the scale and types of morbidity seen across all ages of the OA population.

Another important message from this work is that of collaboration, which has been the key to this project as the patient support groups of Europe worked together towards a common goal. In the literature to date collaboration is limited in OA research as centres have tended to publish their own limited series. More recently larger national and international collaborations have led to more representative studies and with projects such as the European Reference Network of Rare Inherited and Congenital Anomalies (ERNICA) being developed it is hoped clinicians and research groups can learn from the example set by this patient led project and achieve better quality studies and outcomes through wider collaborative work. The EAT study is testimony to the commitment and drive of the OA patient community and support groups to work together and produce clinically relevant and effective research in attempts to improve clinical care. Now that the EAT 1 study has given a broad baseline of the scale of gastroenterological, respiratory and QoL morbidity seen in OA patients, a more detailed and focussed study of a smaller cohort of these patients is being designed. 
Legends:

Table 1: Member organisations of EAT

Figure 1. Respondents by Country

Figure 2. Numbers of dilatations by age

Figure 3. Frequency of food bolus sticking by age

Figure 4. Frequency of respiratory problems

Figure 5. Frequency of chest infections by age

Figure 6. Height and weight by age. A) SDS score in under $18 \mathrm{yrs}, \mathrm{B}) \mathrm{BMI}$ in adult patients

Figure 7. Current care provision by age group

Figure 8. Quality of life. Frequency of impact of OA on A) quality of life, B) on other family members, C) ability to form relationships and D) education or work 


\section{Acknowledgements:}

This collaborative work has involved many different people from the design of the study through to data collection and subsequent analysis.

The advisory work and support of Prof Rene Wijnen, Head of Paediatric Surgery and Professor Monique van Dijk and their colleagues at Sofia Children's Hospital, Erasmus MC is greatly appreciated. Prof van Dijk advised on questionnaire design.

All member groups and the patients of EAT are acknowledged for their assistance in making this study possible.

\section{References}

[1] Burge DM, Shah K, Spark P, Shenker N, Pierce M, Kurinczuk JJ, et al. Contemporary management and outcomes for infants born with oesophageal atresia. Brit J Surg 2013;100(4):515-

21.

[2] Orford J, Cass DT, Glasson MJ. Advances in the treatment of oesophageal atresia over three decades: the 1970s and the 1990s. Pediatr Surg Int 2004;20(6):402-7.

[3] Lopez PJ, Keys C, Pierro A, Drake DP, Kiely EM, Curry Jl, et al. Oesophageal atresia: improved outcome in high-risk groups? J Pediatr Surg 2006;41(2):331-4.

[4] Allin B, Knight M, Johnson P, Burge D. Outcomes at one-year post anastomosis from a national cohort of infants with oesophageal atresia. PLoS One 2014;9(8):e106149.

[5] Castilloux J, Noble AJ, Faure C. Risk factors for short- and long-term morbidity in children with esophageal atresia. J Pediatr 2010;156(5):755-60.

[6] McKinnon LJ, Kosloske AM. Prediction and prevention of anastomotic complications of esophageal atresia and tracheoesophageal fistula. J Pediatr Surg 1990;25(7):778-81.

[7] Roberts K, Karpelowsky J, Fitzgerald DA, Soundappan SS. Outcomes of oesophageal atresia and tracheo-oesophageal fistula repair. J Paediatr Child Health 2016;52(7):694-8.

[8] Connor MJ, Springford LR, Kapetanakis VV, Giuliani S. Esophageal atresia and transitional care--step 1: a systematic review and meta-analysis of the literature to define the prevalence of chronic long-term problems. Am J Surg 2015;209(4):747-59.

[9] Sistonen SJ, Koivusalo A, Nieminen U, Lindahl H, Lohi J, Kero M, et al. Esophageal morbidity and function in adults with repaired esophageal atresia with tracheoesophageal fistula: a population-based long-term follow-up. Ann Surg 2010;251(6):1167-73.

[10] Sistonen S, Malmberg P, Malmstrom K, Haahtela T, Sarna S, Rintala RJ, et al. Repaired oesophageal atresia: respiratory morbidity and pulmonary function in adults. Eur Respir J 2010;36(5):1106-12.

[11] Tadic V, Hogan A, Sobti N, Knowles RL, Rahi JS. Patient-reported outcome measures (PROMs) in paediatric ophthalmology: a systematic review. Bri J Ophthalmol 2013;97(11):1369-81.

[12] Sullivan KJ, Hunter Z, Andrioli V, Guerra L, Leonard M, Klassen A, et al. Assessing quality of life of patients with hypospadias: A systematic review of validated patient-reported outcome instruments. J Pediatr Urol 2017;13(1):19-27. 
[13] Okamoto T, Takamizawa S, Arai H, Bitoh Y, Nakao M, Yokoi A, et al. Esophageal atresia: prognostic classification revisited. Surg 2009;145(6):675-81.

[14] Pedersen RN, Calzolari E, Husby S, Garne E. Oesophageal atresia: prevalence, prenatal diagnosis and associated anomalies in 23 European regions. Arch Dis Child 2012;97(3):227-32.

[15] Dingemann C, Meyer A, Kircher G, Boemers TM, Vaske B, Till H, et al. Long-term healthrelated quality of life after complex and/or complicated esophageal atresia in adults and children registered in a German patient support group. J Pediatr Surg 2014;49(4):631-8.

[16] Little DC, Rescorla FJ, Grosfeld JL, West KW, Scherer LR, Engum SA. Long-term analysis of children with esophageal atresia and tracheoesophageal fistula. J Pediatr Surg 2003;38(6):852-6.

[17] Chetcuti P, Phelan PD. Gastrointestinal morbidity and growth after repair of oesophageal atresia and tracheo-oesophageal fistula. Arch Dis Child 1993;68(2):163-6.

[18] Spoel M, Meeussen CJ, Gischler SJ, Hop WC, Bax NM, Wijnen RM, et al. Respiratory morbidity and growth after open thoracotomy or thoracoscopic repair of esophageal atresia. J Pediatr Surg 2012;47(11):1975-83.

[19] Schneider A, Michaud L, Gottrand F. Prevalence of Barrett Esophagus in Adolescents and Young Adults with Esophageal Atresia. Ann Surg. 2016 Dec;264(6):1004-1008

[20] Krug E, Bergmeijer JH, Dees J, de Krijger R, Mooi WJ, Hazebroek FW. Gastroesophageal reflux and Barrett's esophagus in adults born with esophageal atresia. Am J Gastroenterol 1999;94(10):2825-8.

[21] Sistonen SJ, Koivusalo A, Lindahl H, Pukkala E, Rintala RJ, Pakarinen MP. Cancer after repair of esophageal atresia: population-based long-term follow-up. J Pediatr Surg 2008;43(4):602-5.

[22] Chetcuti F PP. Respiratory morbidity after repair of oesopahageal atresia and tracheooesophageal fistula. Arch Dis Child 1993;68:167-70.

[23] Deurloo JA, Ekkelkamp S, Taminiau JA, Kneepkens CM, ten Kate FW, Bartelsman JF, et al. Esophagitis and Barrett esophagus after correction of esophageal atresia. J of Pediatr Surg 2005;40(8):1227-31.

[24] Deurloo JA, Ekkelkamp S, Bartelsman JF, Ten Kate FJ, Schoorl M, Heij HA, et al. Gastroesophageal reflux: prevalence in adults older than 28 years after correction of esophageal atresia. Ann Surg 2003;238(5):686-9.

[25] Gibreel W, Zendejas B, Antiel RM, Fasen G, Moir CR, Zarroug AE. Swallowing Dysfunction and Quality of Life in Adults With Surgically Corrected Esophageal Atresia/Tracheoesophageal Fistula as Infants: Forty Years of Follow-up. Ann Surg. 2016 Sep 6. [Epub ahead of print]

[26] Dingemann J, Szczepanski R, Ernst G, Thyen U, Ure B, Goll M, et al. Transition of Patients with Esophageal Atresia to Adult Care: Results of a Transition-Specific Education Program. Eur J Pediatr Surg 2017 Feb;27(1):61-67

[27] Campbell F, Biggs K, Aldiss SK, O'Neill PM, Clowes M, McDonagh J, et al. Transition of care for adolescents from paediatric services to adult health services. Cochrane Database Syst Rev 2016;4:CD009794. 
[28] Peetsold MG, Heij HA, Deurloo JA, Gemke RJ. Health-related quality of life and its determinants in children and adolescents born with oesophageal atresia. Acta Paediatr 2010;99(3):411-7.

[29] Deurloo JA, Ekkelkamp S, Hartman EE, Sprangers MA, Aronson DC. Quality of life in adult survivors of correction of esophageal atresia. Arch Surg 2005;140(10):976-80. 
Table 1

\begin{tabular}{|c|c|c|}
\hline \multicolumn{2}{|l|}{ Organisation } & \multirow{2}{*}{$\begin{array}{l}\text { Country } \\
\text { France }\end{array}$} \\
\hline AFAO & Association Francaise de l'Atresie de l'Oesophage & \\
\hline ABeFAO & $\begin{array}{l}\text { Association Belge Francophone de l'Atrésie de } \\
\text { l'Oesophage }\end{array}$ & Belgium \\
\hline FATE & Famiglie con Atresia dell'Esofago & Italy \\
\hline KEKS & Kinder und Erwachsene mit kranker Speiseröhre & Germany \\
\hline KEKS & Kinder und Erwachsene mit kranker Speiseröhre & Austria \\
\hline OARA & Oesophageal Atresia Research Association & Australia \\
\hline OA-Switzerland & OA-Switzerland & Switzerland \\
\hline TOFS & Tracheo-Oesophageal Fistula Support & $\begin{array}{l}\text { United } \\
\text { Kingdom }\end{array}$ \\
\hline TROAD & $\begin{array}{l}\text { Türkiye Özofagus Atrezisi Çocuk ve Aile Destek } \\
\text { Derneği }\end{array}$ & Turkey \\
\hline VOKS & $\begin{array}{l}\text { Vereniging voor Ouderen en Kinderen met een } \\
\text { Slokdarmafsluiting }\end{array}$ & Netherlands \\
\hline AQAO & Association Quebecoise de l'Atresie de l'Oesophage & Canada \\
\hline
\end{tabular}




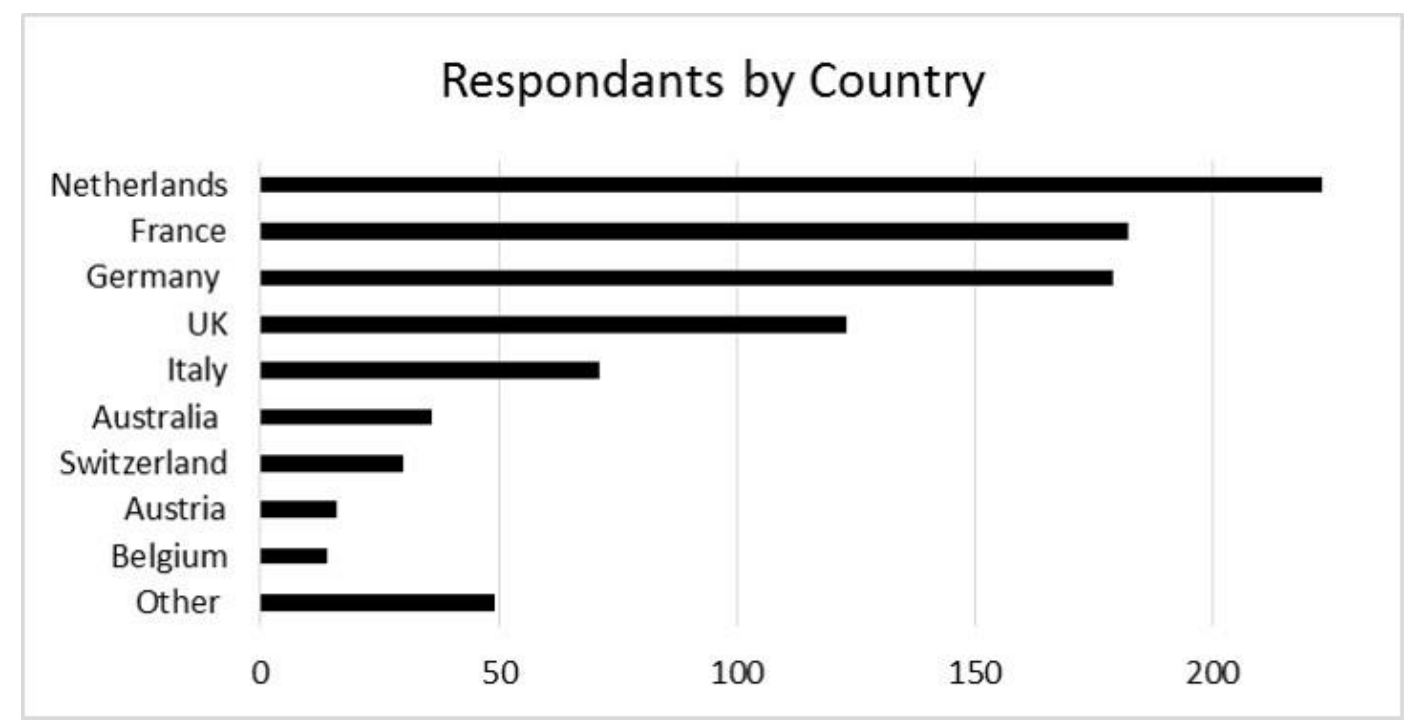

Figure 1

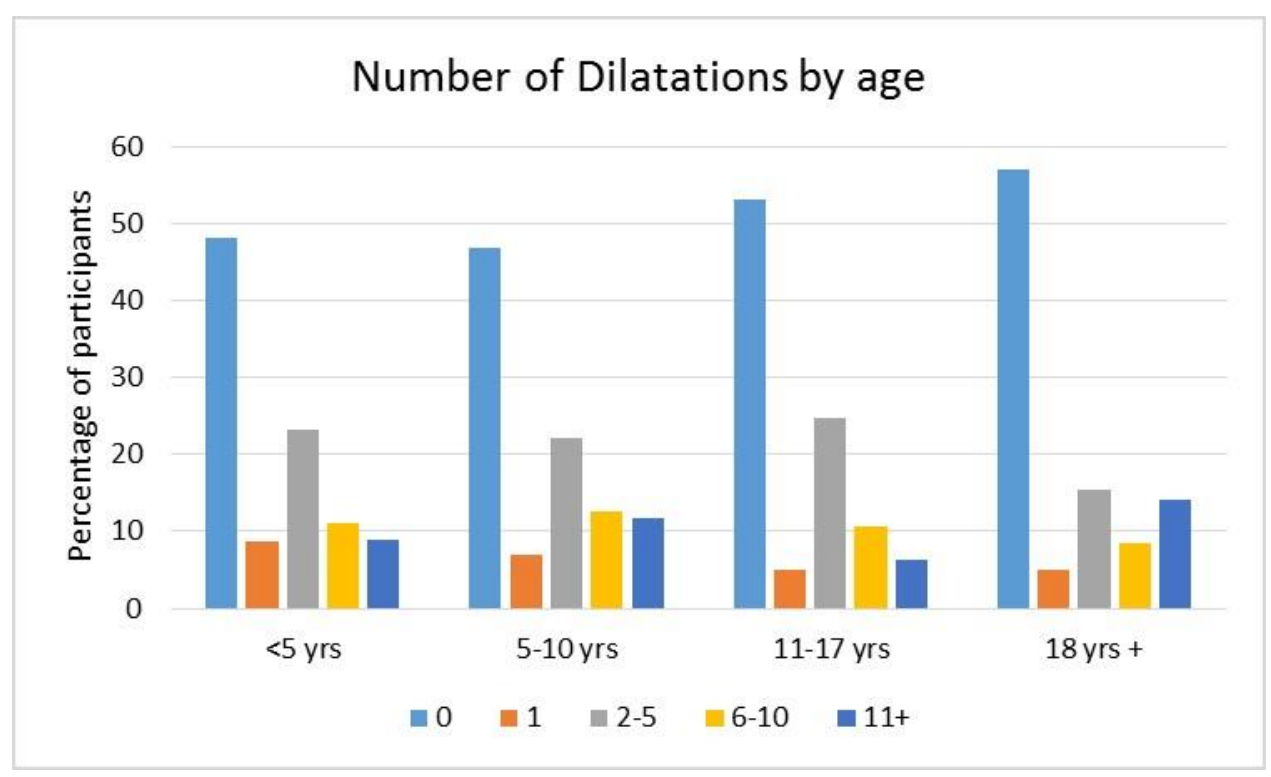

Figure 2

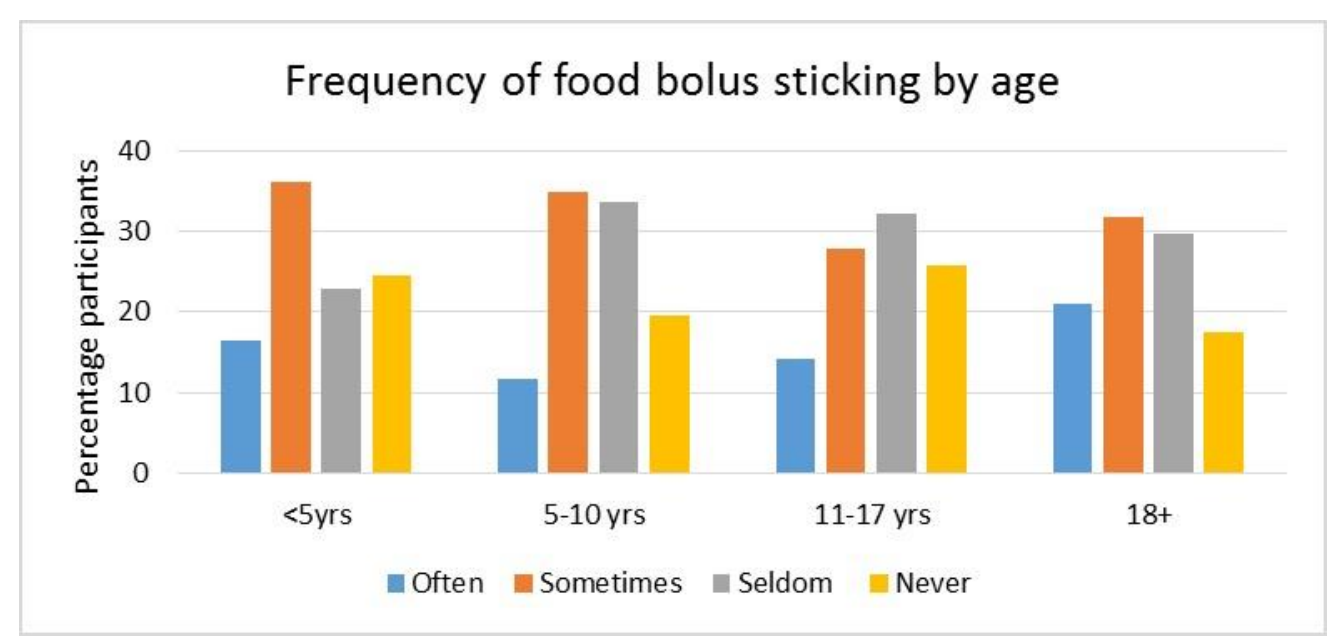

Figure 3 


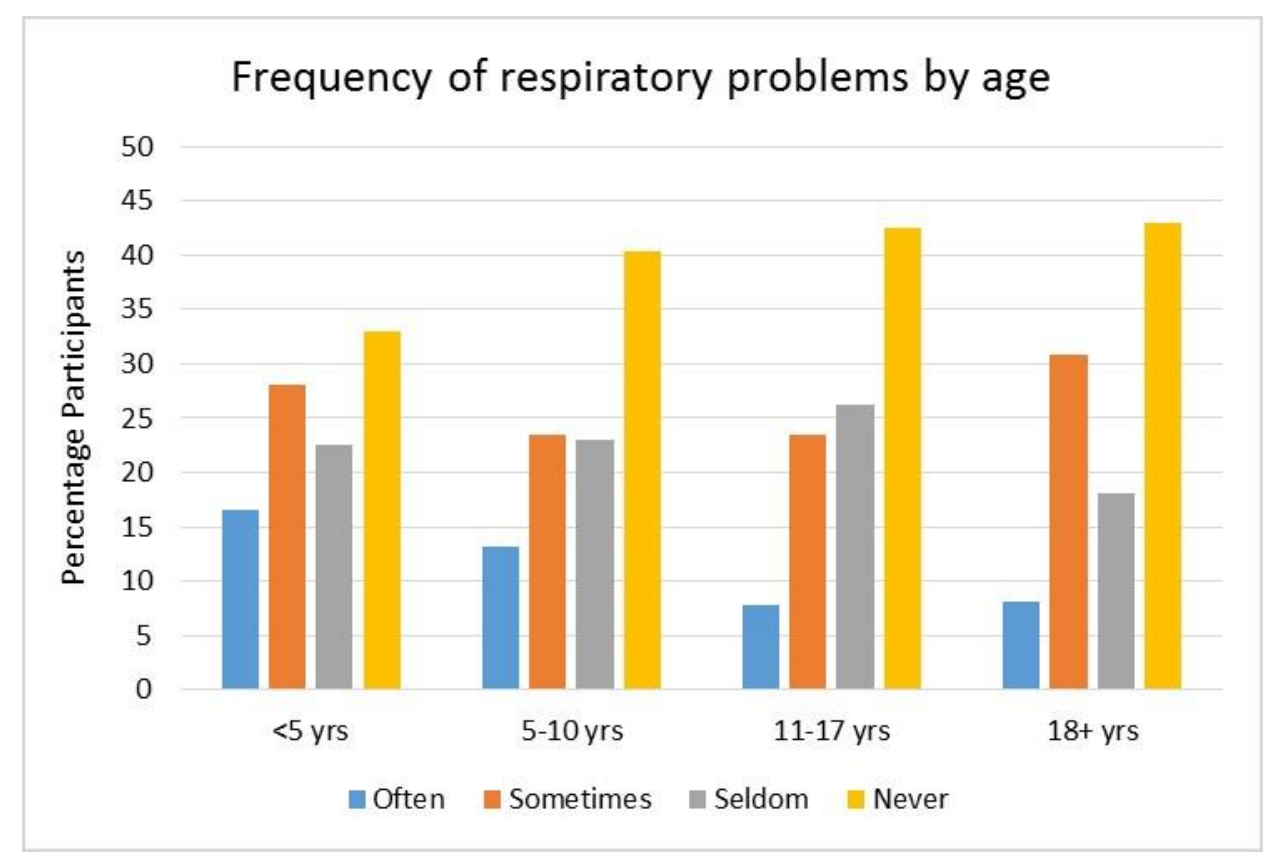

Figure 4

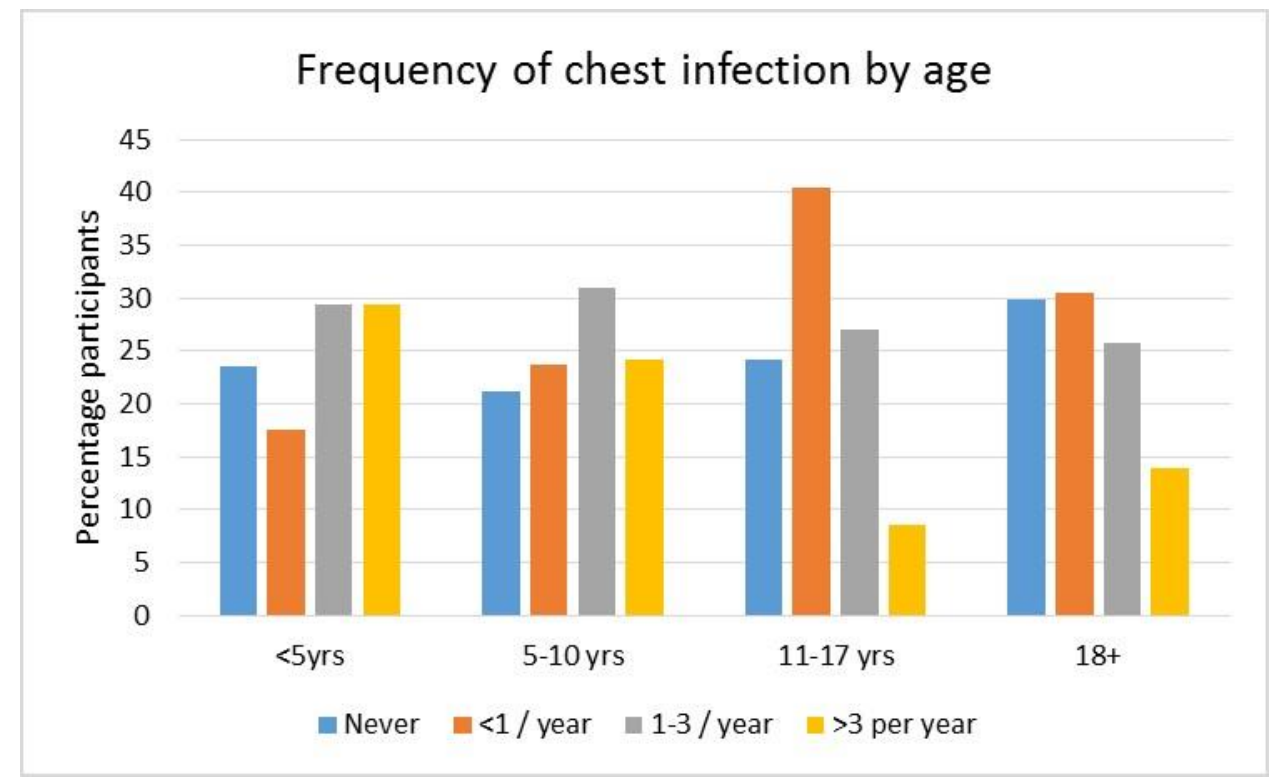

Figure 5 
A

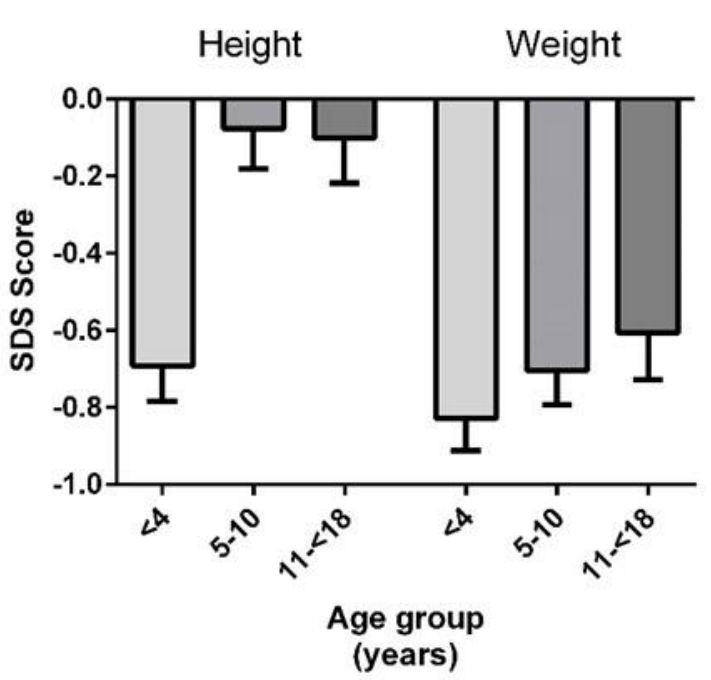

B

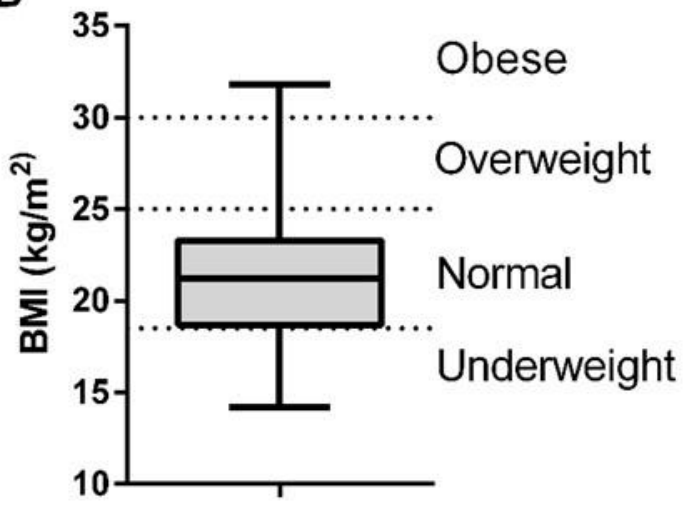

Figure 6

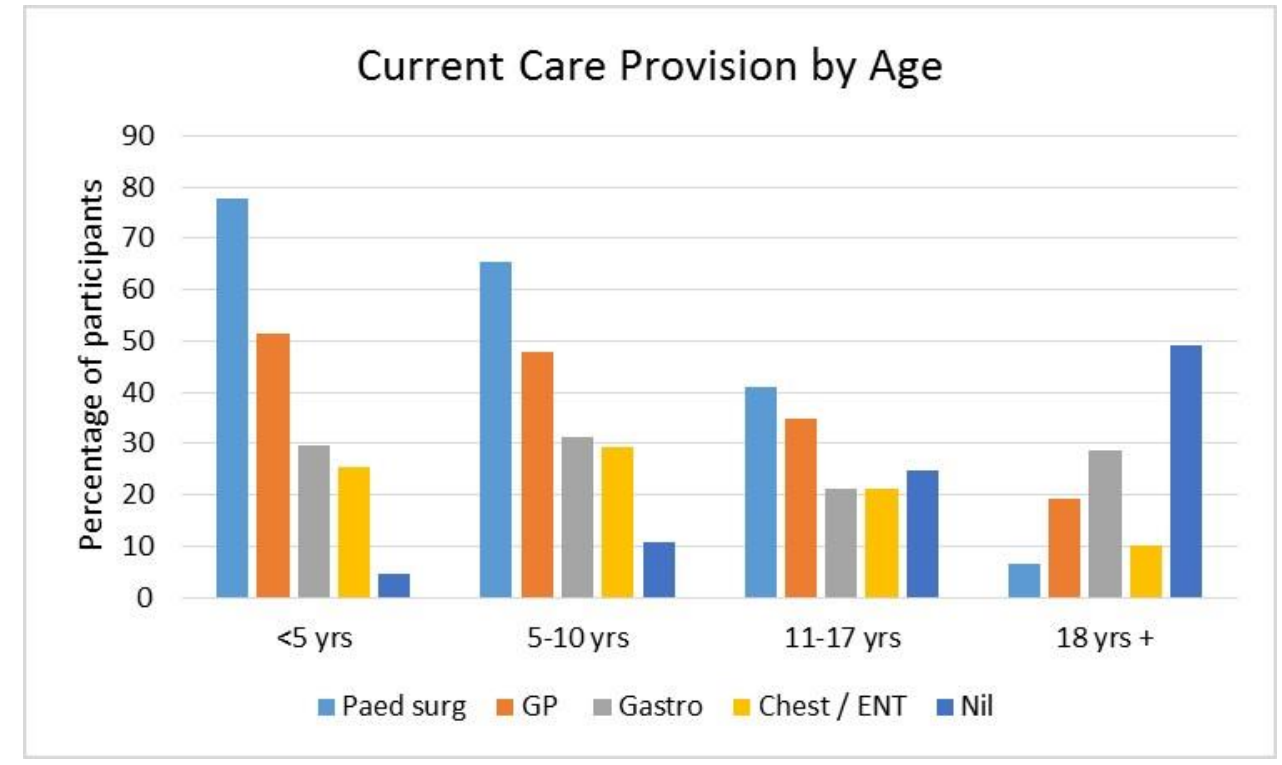

Figure 7 


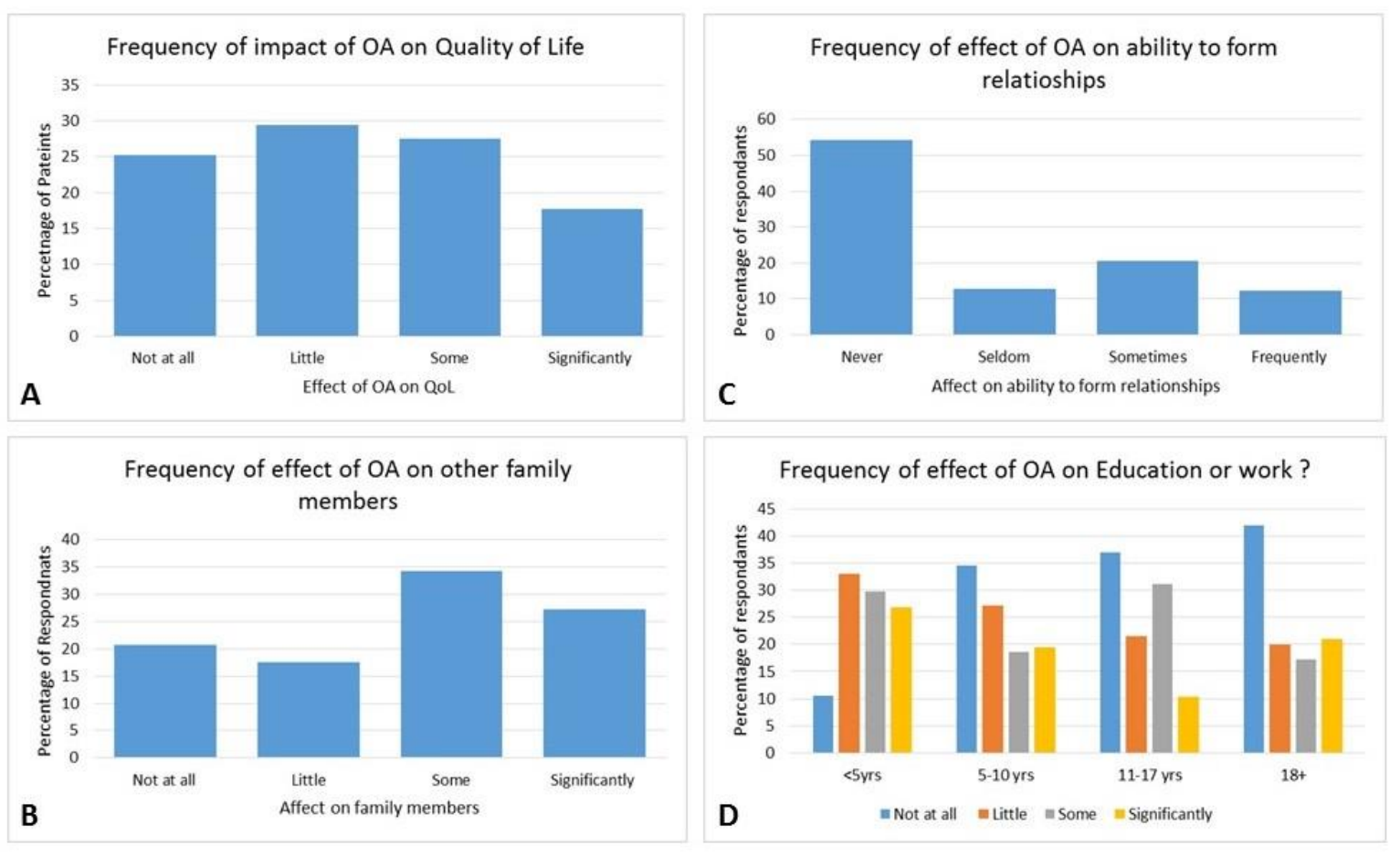

Figure 8 